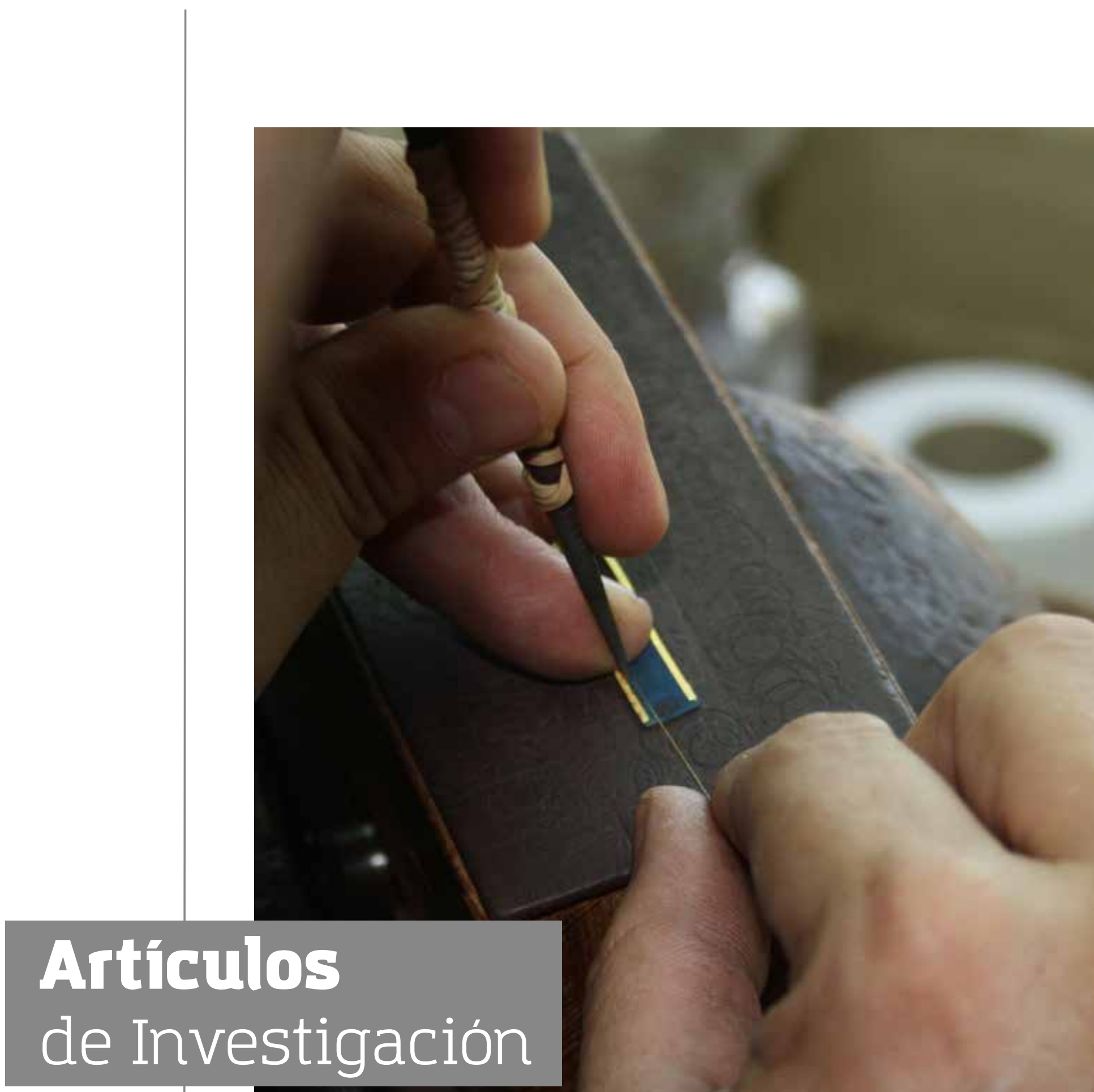




\section{Medios de comunicación y medios sociales en tiempos de COVID-19}

\section{Communication and social media in times of COVID-19}

https: / / doi.org/10.18566/comunica.n45.a02

Recibido: 09 de febrero de 2021

Aceptado: 31 de mayo de 2021

\section{Resumen}

El presente trabajo se propuso identificar el uso, la dependencia y la confianza que se tuvo en los medios de comunicación y los medios sociales al inicio de la cuarentena decretada por el Estado mexicano con motivo de la llegada del nuevo coronavirus a México. Para responder al objetivo señalado se recurrió a la técnica de la encuesta. Los resultados indican que durante el periodo de la cuarentena hubo un aumento notable tanto del uso de los medios de comunicación como de los medios sociales. También muestran que aun cuando las evidencias dan fe de que los medios sociales (internet y sus aplicaciones) fueron las herramientas más utilizadas, en la ciudad de Monterrey (Nuevo León) y su área metropolitana las personas respondieron que los medios de comunicación fueron el recurso que les ofreció la mejor información sobre el tema. En específico, sostienen que fueron los noticieros de televisión el recurso del cual obtuvieron la información más confiable para tomar las decisiones y afrontar la crisis de salud.

\section{Abstract}

The present work aimed to identify the use, dependence and trust that was had in the media and social media at the beginning of the quarantine decreed by the Mexican State on the occasion of the arrival of the coronavirus in Mexico. The methodology used in order to respond to the initially proposed objective was the survey technique. The results indicate that during the quarantine period both the use of the mass and social media increased notably. The results show that, even when the evidence indicates that social media (internet and its different apps) were the most used tools during
Comunicación

número 45

Julio - diciembre

2021 | pp. 14-29

\section{Dr. Francisco Javier Martínez Garza}

Profesor investigador de la Universidad Autónoma de Nuevo León y doctor por la Universidad de Sevilla. Miembro del Sistema Nacional de Investigadores en México (SNI) nivel 1. Coordinador general del Posgrado e Investigación de la Universidad Autónoma de Nuevo León.

francisco.martinezg@uanl. edu.mx

https: / / orcid.org/00000001-7405-9724

\section{Dra. Margarita Emilia González Treviño}

Profesora investigadora de la Universidad Autónoma de Nuevo León.

Doctora en Educación por la Nova Southeastern University margarita.gonzaleztr@uanl. edu.mx https: / / orcid.org/00000002-0945-4346 
the quarantine, in the city of Monterrey (Nuevo Leon) and its metropolitan area, people indicated that the mass media was the source that offered them the best information on the subject. Specifically, the people surveyed maintained that television newscasts were the source from which they obtained the most reliable information to make decisions to face the health crisis that prevailed during that time.

\section{Introducción}

Los últimos días de enero de 2020, los medios de comunicación y las redes sociales destacaban entre sus mensajes la llegada inminente a México de una enfermedad llamada COVID-19. La Organización Mundial de la Salud (OMS) (2020) alertaba que se trataba de una enfermedad infecciosa derivada de la familia coronavirus, cuyo origen remitía a la ciudad de Wuhan, en China. Conforme transcurrían los días, el tema ocupaba mayor espacio en los recursos de comunicación e información, hasta que se dio a conocer el primer caso de infección en México la última semana de febrero. Un mes después, las autoridades gubernamentales decretaron un período de cuarentena, con el objetivo de mitigar los estragos que para entonces se presentaban en otros países. La disposición incluyó la suspensión de todo tipo de actividades no esenciales en los sectores públicos, social y privado durante un mes.

Transcurrido el período acordado de inactividad, los contagios y las muertes se mantenían al alza y las condiciones sanitarias calificadas como de alto riesgo. Ante esa situación, las autoridades decidieron recomendar a la población permanecer en casa el mayor tiempo posible. Fue así como los hogares de pronto se convirtieron en centros educativos y en oficinas de trabajo.

Pasar mayor tiempo en el hogar se traducía en que las personas dedicaran una mayor cantidad de tiempo a los medios de comunicación y a los medios sociales, para recibir y enviar información, a la vez que mantenerse en contacto con otros que como ellos padecían los estragos del encierro. Este momento ha sido el de mayor protagonismo de estos sistemas en México.

Considerando las condiciones y el papel que tomaron las tecnologías de comunicación e información, el presente trabajo se propuso identificar el uso, dependencia y confianza que establecieron los habitantes y las habitantes de Monterrey, Nuevo León, frente a medios de comunicación y medios sociales durante la pandemia. Para responder sistemáticamente al planteamiento formulado, se prepararon las siguientes preguntas de investigación:
15

comunicación

número 45

Julio - diciembre

2021

\section{Palabras clave}

Medios de comunicación, Medios sociales, COVID-19, Uso de medios.

\section{Keywords}

Media, Social media, COVID-19, Use of media.

1 Para efectos del presente trabajo son medios de comunicación la televisión, la prensa y la radio, y medios sociales todas aquellas aplicaciones soportadas en internet, las cuales, a diferencia de las primeras, permiten el acceso, creación e intercambio de contenidos. En esta misma categoría se incluye WhatsApp, considerada un sistema de mensajería, pero durante el período de la cuarentena tuvo una injerencia destacada en el intercambio de contenidos informativos. 
- ¿Cómo utilizaron las personas los medios de comunicación y los medios sociales durante el período analizado?

- ¿ ¿En qué medida se expusieron a los diferentes recursos de comunicación para mantenerse al tanto de la situación que imperaba en torno al coronavirus?

- ¿Cuál fue el recurso o sistema de comunicación en el que depositaron mayor confianza para conocer los pormenores de la situación?

El estudio permitirá saber cómo fue que utilizaron las personas las diversas tecnologías bajo condiciones distintas a las que ordinariamente suelen enfrentar en su vida cotidiana. El material con el que se respondió a los cuestionamientos planteados está soportado en información obtenida de una encuesta realizada entre habitantes de Monterrey y su área metropolitana. La considerada segunda zona urbana más grande de México se localiza al noreste y cuenta con poco más de cinco millones de habitantes.

En la ciudad reside el 91 \% del total de habitantes del estado de Nuevo León y de acuerdo con las cifras del último Censo Nacional de Población y Vivienda (Instituto Nacional de Estadística y Geografía [Inegi], 2021), poco menos del $70 \%$ de los hogares tiene internet y el 93 \% de las personas tiene servicio de telefonía celular; además, uno de cada dos tiene computadora. Finalmente, el uso que hacen alli de las tecnologías digitales supera ampliamente la media del resto del país.

\section{Revisión de literatura}

La información procedente del extranjero que aludía a los estragos que el COVID-19 estaba provocando, sobre todo en países europeos, incrementaba el temor de los mexicanos, por lo que para reducir su incertidumbre procuraban enterarse del evento echando mano de los recursos a su alcance. Lo anterior se convirtió en una práctica generalizada en todo el mundo. Una encuesta hecha en 17 países de distintos continentes concluyó que durante la pandemia la mayoría de las personas estaban preocupadas y temerosas de infectarse o de transmitir el virus (Stoychev, 2020). El estudio refiere que el temor al virus era de tal magnitud que incluso una parte de la población (17 \%) estaba dispuesta a sacrificar algunos de sus derechos humanos para evitar o prevenir la propagación de la infección.

En México la situación no fue distinta: el uso de los recursos de comunicación e información fue similar al reportado anteriormente (IAB México, 2020). Seis de cada diez internautas dijeron haber recurrido con mayor frecuencia a sus aplicaciones digitales durante la pandemia. Al mismo tiempo, reconocieron haber incrementado el consumo de la TV abierta (10 \%) y de paga (4\%). La 
prensa digital y las plataformas streaming también mostraron un notable incremento en su consumo.

Lo que más llama la atención es que aun cuando las evidencias muestran que el tráfico de internet se elevó casi 25 \% en el mundo, la televisión fue el recurso informativo más usado para enterarse sobre lo que sucedía con el COVID-19. En Estados Unidos y en Reino Unido, el 68 \% de las consumidoras y los consumidores dijeron haber utilizado distintos sistemas o recursos de comunicación para informarse sobre el coronavirus, pero la mayoría (80 \%) mencionó a la televisión y al video en línea como los recursos que más utilizó a partir de la irrupción del virus (González, 2020).

El hecho de preferir la televisión por encima de cualquier otro recurso pareciera no ser un caso aislado, ya que las evidencias indican que este medio se convirtió en la alternativa más utilizada para conocer sobre el COVID-19 en distintas partes del planeta, presentándose así lo que algunos autores denominaron "el renacimiento de la televisión" (Vázquez, 2020). Un estudio hecho en Kenia y en Uganda (McCroclin, 2020; Elliot, 2020) concluyó que el promedio de tiempo que las personas dedicaron a mirar noticieros de televisión creció notablemente durante ese período. En Argentina, Alemania, Corea del Sur, España, Reino Unido y Estados Unidos la televisión se impuso también como el medio más utilizado para estar al tanto del COVID-19 (Stoychev, 2020).

Una explicación del porqué las personas prefieren la televisión antes que otros medios para informarse sobre la pandemia, incluso por encima de los medios sociales, no obstante las bondades que se les atribuyen a estos últimos, es esta: cuando se trata de situaciones de alto riesgo, aquellas confieren mayor credibilidad a los medios tradicionales, como lo es la televisión, ya que a diferencia de lo que ocurre con las redes sociales, suele filtrarse y verificarse la información que se difunde (Muno, 2020; Pulido et al., 2020). Todo apunta a presuponer que los medios sociales no han obtenido del todo la confianza de los usuarios, a pesar de los notables esfuerzos para evitar que circulen contenidos falsos.

En sí, la aparición y distribución de contenidos falsos no es producto de los medios sociales: este tipo de mensajes tiene un largo recorrido. Lo que importa en este caso es considerar que la enorme popularidad que han alcanzado podría convertir la difusión de información falsa en un problema mundial (Oberiri Destiny, y Bahiyah, 2017; Zhou y Zafarani, 2020). Transmitir en los medios sociales contenidos falsos bajo un ambiente de crisis podría terminar por impactar la percepción que las personas tienen de la realidad (Ireton y Posetti, 2018; Lazer et al., 2018). El riesgo es mayúsculo cuando se trata de situaciones que ponen en peligro la vida, como ha ocurrido 
durante la pandemia. Existe evidencia de mensajes sobre curas y consejos para hacer frente al COVID-19. Lampos et al. (2021) reportan mensajes que circularon en los medios sociales que sugerían beber agua salada o lejía, e incluso comer orégano como medidas para evitar la enfermedad.

El comportamiento que muestran las personas al seleccionar a la televisión por encima de otros medios, que a su juicio podrían ser menos confiables, conduce a reconsiderar su capacidad para elegir los recursos y mensajes que a su juicio son los más apropiados para informarse (Katz et al., 1986). Desde los usos y gratificaciones se presupone que los usuarios son capaces de seleccionar por sí mismos de entre las diversas opciones de información que tienen a su alcance cuál es la que mejor satisface sus necesidades (Greenberg, 1974). Considerando lo anterior, no sorprende, por lo tanto, que bajo las condiciones de apremio que se suscitaron, los usuarios hayan preferido recurrir a los medios de comunicación tradicionales, antes que a los medios sociales, para aprender y conocer más acerca del virus.

La mayoría de los estudios relacionados con la propuesta de los usos y las gratificaciones sostienen que estas responden a disposiciones psicológicas individuales, factores sociológicos y condiciones ambientales. Finalmente, son estos factores los cuales determinan el uso que el público hará de ellos (Lozano, 2007). Desde un principio, esta propuesta se enfocó en el uso de los medios tradicionales, pero recientemente su aplicación se ha extendid o hacia internet, sobre todo a los medios sociales (Thompson et al., 2019). Autores como Park y Blenkinsopp (2009) han establecido gratificaciones asociadas al uso de estas, entre las que se destacan la búsqueda de información y la socialización, aspectos que están directamente vinculados con las situaciones vividas durante la pandemia.

Recurrir a los medios de comunicación para informarse y dejar en segundo plano a los medios sociales cuando se trata de afrontar situaciones de alto riesgo es un comportamiento en el cual ya se había reparado. De hecho, usos y gratificaciones también hacían referencia a cómo se conducirían las personas al seleccionar los medios de donde obtendrían información. Sin embargo, un análisis enfocado en el marco de la Primavera Árabe ofrece más evidencia sobre esta última situación.

El estudio, llevado a cabo por Pippa Norris (2015), analizó el uso de los recursos de información a los que accedieron las personas durante los hechos ocurridos en la Primavera Árabe. En su trabajo afirma que no debería sobredimensionarse la participación que tuvieron los medios sociales. Tomando como referencia los sondeos de Zogby en 2011 (citada en Norris, 2015), la autora halló que no fueron las redes sociales, sino la televisión, el recurso que más utilizó la gente para informarse del tema, especialmente 
los noticieros que se transmitían vía satélite. Así, Norris afirma que la televisión, y no los medios sociales, fue el medio más usado y en el cual más confiaban los habitantes de los países incluidos en la muestra del sondeo hecho por Zogby.

El sondeo incluía Túnez, Egipto, Líbano, Jordania, Arabia Saudita y los Emiratos, y en todos ellos, de acuerdo con Norris (2015), sobresalía la exposición que tenían a las televisoras nacionales y locales para mantenerse informadas sobre los problemas del momento. Cuando les era posible, accedían a la televisión vía satélite. Por lo anterior, Norris sostiene que durante los momentos de incertidumbre los medios sociales son utilizados principalmente para fortalecer y mantener activas las comunicaciones personales, pero las emisiones televisivas, como sucedió con las cadenas Al Jazeera y Al Arabiya, se convierten en las fuentes de información principales.

\section{Método de trabajo}

Los resultados que se presentan a continuación están respaldados en una encuesta aplicada a hombres y mujeres mayores de 15 años, residentes en la ciudad de Monterrey, Nuevo León, y su área metropolitana. Ubicada al noreste del país, la ciudad está conformada por una población de 5.300.000 millones (Inegi, 2021) y destaca por encima del resto de las poblaciones mexicanas por el dinamismo de su economía, sus servicios de educación y salud, y por los indicadores de acceso y consumo de internet, los cuales superan la media nacional (García, 2019).

Tomando en consideración las condiciones de riesgo que prevalecieron en la ciudad a partir de marzo de 2020, y en congruencia con las disposiciones de las autoridades universitarias y gubernamentales, se decidió aplicar la encuesta en la plataforma electrónica Google Forms. El instrumento, que incorporó 16 preguntas, estuvo en la plataforma del 18 al 30 de mayo. Participaron 45 estudiantes de la materia Metodología de la Investigación, de la Facultad de Ciencias de la Comunicación de la Universidad Autónoma de Nuevo León.

Los estudiantes conocían a detalle los objetivos que se perseguían con la aplicación de la encuesta y se les capacitó en el manejo del programa. Entre las recomendaciones más importantes se destacan las siguientes: primero, que la encuesta fuera aplicada a personas mayores de 15 años; segundo, que fueran integradas en su muestra personas de diferente género; y, sobre todo, que fueran incluidos como mínimo tres hombres mayores de 30 años, ya que este segmento de la población es dificil de contactar (son quienes menos tiempo permanecen en el hogar). En la capacitación, control 
y verificación de la información participaron tres docentes de la misma institución.

Al cierre de la captura se contabilizaron 1093 encuestas. Sin embargo, se trabajó con una muestra inferior, por cuanto toda encuesta que mostraba alguna inconsistencia era eliminada. Los docentes verificaron la información, seleccionando aleatoriamente algunas encuestas y comunicándose con el encuestado. En caso de encontrar alguna incongruencia, se eliminaba completamente. El procedimiento impactó directamente en el tamaño de la muestra, que se redujo hasta ubicarse en 719. Para identificar la consistencia del instrumento, se recurrió al coeficiente de confiabilidad alfa de Cronbach y se obtuvo, de acuerdo con la literatura (Arévalo Avecillas y Padilla Lozano, 2016), un buen nivel de fiabilidad: $\alpha=0,749$.

\section{Resultados}

El estudio se propuso identificar la relación que establecieron los habitantes de Monterrey y su área metropolitana con los medios de comunicación y los medios sociales durante la cuarentena. Fueron entrevistadas 719 personas entre 15 y 65 años o más. La mayoría de ellos (62 \%) dijeron haber recurrido mucho a los medios tradicionales o sociales durante la pandemia del COVID-19. Las evidencias indican que durante este período tres de cada cuatro personas $(77 \%)$ reconocieron haber dedicado más tiempo del ordinario a estas tecnologías. Bajo las condiciones impuestas por la cuarentena, casi la mitad de los encuestados (48 \%) reconoció buscar información, principalmente en los medios tradicionales, como televisión, prensa o radio, para estar al tanto de la situación.

\section{Medios de comunicación y medios sociales durante la pandemia}

La mayoría de los ciudadanos y las ciudadanas (52 \%) se informaban en más de un medio y procuraban estar al tanto de lo que sucedía, por lo cual se exponían frecuentemente a los comunicados oficiales. Poco más de las dos terceras partes de los encuestados (67 \%) usualmente platicaban sobre el tema con la familia, sobre todo los hombres (72\%), quienes más lo hacían, situación que se reafirma con la Chi Cuadrada $\left(x^{2}=.018\right)$. Aun así, el coeficiente de contingencia (C. $C .=.17)$ indica que el género no es un elemento que incida en el hecho de platicar o no sobre el tema con la familia.

Durante la cuarentena, las redes sociales se convirtieron también en aliadas de las personas. Casi tres de cada cuatro encuestados (77\%) manifestaron que estas contribuyeron a sobrellevar más fácilmente el encierro. Lo anterior ocurrió principalmente en jóvenes de entre 15 y 24 años. Conviene destacar que la percepción de las personas mayores ( $\geq 25$ años) y la de 
los jóvenes no fue muy distinta. De acuerdo con las evidencias, en primera instancia pareciera que las más jóvenes reconocen el papel que cumplieron los medios sociales para sobrellevar la pandemia (Chi Cuadrada $x^{2} 2=.001$ ). Sin embargo, en realidad la edad no incidió mucho en la percepción que se crearon las personas (C. C. $=.187$ ).

Lo anterior se refuerza aún más si se repara en que las evidencias muestran que en términos generales las personas hicieron mayor uso del que ordinariamente hacen de las redes sociales. La mayoría (76 \%) señaló que ordinariamente se mantenía conectado a estas, sin importar aquí el género - la edad del encuestado. Aun cuando el estadístico de la Chi Cuadrada sugiere que la edad incide entre permanecer conectado o no a las redes sociales $\left(x^{2} 2=.020\right)$, al igual que en los análisis anteriores, el impacto de la edad para estar o no conectado a los medios sociales la mayoría del tiempo es reducido (C. C. $=.169$ ).

A pesar de que los medios sociales fueron muy utilizados durante la cuarentena, no necesariamente ocurrió para estar al tanto de las noticias o acontecimientos relacionados con el coronavirus. El estudio muestra que uno de cada dos encuestados sí recurrió a ellos para informarse, siendo los adultos quienes más lo hicieron. Aun así, no existe ninguna evidencia estadísticamente significativa que corrobore que la edad sea algún factor determinante para utilizar los medios sociales con el fin de informarse. Sin embargo, el género sí muestra una evidencia estadísticamente significativa $\left(x^{2} 2=.001\right)$. De acuerdo con el estudio, los hombres fueron quienes más recurrieron a los medios sociales para informarse del tema, pero, igual que sucedió en análisis previos, el género en realidad no incidió en el uso o no de los medios sociales para informarse (C. C. = .166).

Entre los medios sociales, el sistema de mensajería WhatsApp fue uno de los más utilizados durante la cuarentena. En promedio, los usuarios y las usuarias lo empleaban casi los siete días de la semana (6,5 días), sobre todo las mujeres. Las plataformas de streaming también fueron muy utilizadas. En este renglón se destacó Netflix: en promedio, los regiomontanos se expusieron a esta casi cuatro días a la semana, siendo las mujeres de entre 30 y 44 años quienes más lo hicieron. El 77 \% de los encuestados dijeron usarla casi todos los días para mirar principalmente series. El consumo de Netflix fue muy similar entre personas de diferente edad, género e incluso nivel de escolaridad.

\section{El recurso más utilizado para informarse del COVID-19}

La encuesta indica que durante la cuarentena la probabilidad de que las personas residentes del área metropolitana de Monterrey consultaran 
información relacionada con el COVID-19 en los medios de comunicación o en las redes sociales fue muy alta. Sin embargo, se ve una notable diferencia en la frecuencia con la que utilizaron cada una de ellas. En ese sentido sobresalen internet, noticieros de televisión y prensa en su versión digital. La prensa y la radio fueron los medios de comunicación menos utilizados por los encuestados para mantenerse al tanto de los pormenores relacionados con la pandemia. La prensa, a pesar de ser un medio que ofrece una mayor cantidad de mensajes, fue poco demandada. Esto se refleja independientemente de la edad o del género. La radio fue el medio menos usado: casi la mitad de los entrevistados (49 \%) dijeron que era poco o nada probable que recurrieran a ella para informarse (Tabla 1).

En la cuarentena los noticieros de televisión se convirtieron en uno de los recursos predilectos para informarse en Monterrey y su área metropolitana. Dos de cada tres personas señalaron que era muy probable o algo probable que recurrieran a este medio para conocer del tema. Aun cuando la respuesta se presentó por igual entre todos, hubo, de acuerdo con la Chi Cuadrada $\left(x^{2} 2=.000\right)$ mayor probabilidad de que los adultos fueran quienes más frecuentemente sintonizaran estos espacios televisivos para ponerse al tanto de la situación.

Tabla 1. Medio al que recurrieron más frecuentemente para informarse sobre la pandemia de acuerdo con género y edad

\begin{tabular}{|l|c|c|c|c|c|c|c|}
\hline \multirow{2}{*}{$\begin{array}{c}\text { Medio } \\
\text { utilizado }\end{array}$} & \multicolumn{3}{|c|}{$\begin{array}{c}\text { Hombre } \\
\text { Edad }\end{array}$} & \multicolumn{3}{c|}{$\begin{array}{c}\text { Mujer } \\
\text { Edad }\end{array}$} & \multirow{2}{*}{ Total } \\
\cline { 2 - 7 } & $15-29$ & $30-44$ & + de 45 & $15-29$ & $30-44$ & + de 45 & \\
\hline Prensa & $8 \%$ & $8 \%$ & $2 \%$ & $6 \%$ & $8 \%$ & $3 \%$ & $6 \%$ \\
\hline Not. TV & $33 \%$ & $35 \%$ & $46 \%$ & $32 \%$ & $28 \%$ & $52 \%$ & $36 \%$ \\
\hline Not. radio & $1 \%$ & $2 \%$ & $6 \%$ & $0 \%$ & $1 \%$ & $1 \%$ & $1 \%$ \\
\hline Prensa digital & $6 \%$ & $16 \%$ & $19 \%$ & $7 \%$ & $14 \%$ & $12 \%$ & $11 \%$ \\
\hline Internet & $37 \%$ & $35 \%$ & $22 \%$ & $41 \%$ & $47 \%$ & $30 \%$ & $38 \%$ \\
\hline Otro & $15 \%$ & $4 \%$ & $5 \%$ & $14 \%$ & $2 \%$ & $2 \%$ & $8 \%$ \\
\hline Total & $100 \%$ & $100 \%$ & $100 \%$ & $100 \%$ & $100 \%$ & $100 \%$ & $100 \%$ \\
$(n=98)$ & $(n=49)$ & $(n=54)$ & $(n=255)$ & $(n=145)$ & $(n=118)$ & $(n=719)$ \\
\hline
\end{tabular}

Fuente: Elaboración propia.

Con la prensa digital hubo una situación similar al resultado relacionado con los informativos de televisión: la mayoría señaló que era muy probable que durante la cuarentena acudiera a la información alli presentada. Al igual que sucede con los telediarios, la probabilidad de que los mayores ( $\geq 45$ años) sean quienes los consulten más frecuentemente era mayor $\left(x^{2}=.000\right)$. 
Sin embargo, el impacto de la edad en el uso de estos espacios es bajo (C. C. $=$.194), por lo que se descarta también que la edad incidiera en la exposición o no a la prensa digital.

Los resultados indican que los encuestados prefirieron recurrir a internet para acceder a la información relacionada con el COVID-19. Nueve de cada diez entrevistados(as) dijeron que era muy probable o probable que bajo las condiciones que prevalecían entonces recurrieran a internet. En ese sentido, los resultados son muy consistentes y no se presenta ninguna diferencia estadísticamente significativa independientemente de la edad, el género o incluso el nivel de escolaridad.

\section{La información más completa del Covid-19}

Aunque internet fue considerado el recurso con mayor probabilidad de ser consultado diariamente para conocer de la pandemia, no fue este recurso calificado como la mejor fuente de información: los noticieros de televisión fueron los que ofrecieron los mejores contenidos para conocer del tema, según los encuestados (Tabla 2 ).

Tabla 2. Medio al que consideran la mejor fuente de información sobre la pandemia, de acuerdo con su género y edad

\begin{tabular}{|c|c|c|c|c|c|c|c|}
\hline \multirow{2}{*}{$\begin{array}{c}\text { Medio } \\
\text { utilizado }\end{array}$} & \multicolumn{3}{|c|}{$\begin{array}{c}\text { Hombre } \\
\text { Edad }\end{array}$} & \multicolumn{3}{|c|}{$\begin{array}{c}\text { Mujer } \\
\text { Edad }\end{array}$} & \multirow[t]{2}{*}{ Total } \\
\hline & $15-29$ & $30-44$ & + de 45 & $15-29$ & $30-44$ & + de 45 & \\
\hline Prensa & $10 \%$ & $8 \%$ & $11 \%$ & $11 \%$ & $7 \%$ & $7 \%$ & $9 \%$ \\
\hline Not. TV & $29 \%$ & $29 \%$ & $46 \%$ & $38 \%$ & $31 \%$ & $48 \%$ & $37 \%$ \\
\hline Not. radio & $3 \%$ & $2 \%$ & $6 \%$ & $0 \%$ & $3 \%$ & $3 \%$ & $2 \%$ \\
\hline Prensa digital & $12 \%$ & $20 \%$ & $17 \%$ & $15 \%$ & $23 \%$ & $9 \%$ & $16 \%$ \\
\hline Internet & $30 \%$ & $39 \%$ & $13 \%$ & $25 \%$ & $26 \%$ & $28 \%$ & $26 \%$ \\
\hline Otro & $16 \%$ & $2 \%$ & $7 \%$ & $11 \%$ & $10 \%$ & $5 \%$ & $10 \%$ \\
\hline Total & $\begin{array}{l}100 \% \\
(n=98)\end{array}$ & $\begin{array}{l}100 \% \\
(n=49)\end{array}$ & $\begin{array}{l}100 \% \\
(n=54) \\
\end{array}$ & $\begin{array}{c}100 \% \\
(n=255)\end{array}$ & $\begin{array}{c}100 \% \\
(n=145)\end{array}$ & $\begin{array}{c}100 \% \\
(n=118)\end{array}$ & $\begin{array}{l}100 \% \\
(n=719) \\
\end{array}$ \\
\hline
\end{tabular}

Fuente: Elaboración propia.

La opinión sobre la calidad de la información que ofrecieron los noticieros de televisión es muy clara; de manera que la preferencia que tienen por este recurso superó por casi 10 puntos porcentuales a internet, el segundo medio mejor evaluado, y por más de 20 a la prensa digital, tercera mejor fuente, de acuerdo con la encuesta. Si se repara en algunas categorías, es 
posible reconocer que existen segmentos de la población que sostienen a los noticieros de televisión como la mejor fuente informativa, pero no todos ni todas coinciden en lo anterior.

El segmento de la población que menos coincide con la idea de que los noticieros de televisión constituyeron la mejor fuente de información sobre el COVID-19 fue el de hombres de entre 30 y 44 años; ellos consideran que el mejor medio fue internet. Esta situación pone de relieve que la edad y el género sí inciden en esta opinión. El estadístico Chi Cuadrada refiere, en efecto, que sí existe una relación estadísticamente significativa entre la edad y la opinión sobre la calidad informativa de los distintos medios $\left(x^{2}=.028\right)$. Se trata de un impacto regular, de acuerdo con el C. C. (C. C. = .301).

\section{La información más confiable sobre el Covid-19}

Los resultados anteriores conducen a responder un tercer cuestionamiento, el cual tiene que ver con la confianza que los encuestados depositaron en el contenido al cual se expusieron. Por una parte, los resultados destacan el papel de internet como proveedor de contenidos, ya que este recurso fue, según los entrevistados, al que se expusieron más frecuentemente durante el período de la pandemia; pero ellos mismos reconocen también que fue en los noticieros de televisión donde consiguieron acceder a los mejores contenidos.

Las evidencias indican que fueron también los noticieros de televisión el recurso informativo en el cual la mayoría confió más (Tabla 3).

Tabla 3. Medio que consideran como el más confiable en el manejo de la información relacionada con el CoVID-19, de acuerdo con su género y edad

\begin{tabular}{|c|c|c|c|c|c|c|c|}
\hline \multirow{2}{*}{$\begin{array}{c}\text { Medio } \\
\text { utilizado }\end{array}$} & \multicolumn{3}{|c|}{$\begin{array}{c}\text { Hombre } \\
\text { Edad }\end{array}$} & \multicolumn{3}{|c|}{$\begin{array}{l}\text { Mujer } \\
\text { Edad }\end{array}$} & \multirow[t]{2}{*}{ Total } \\
\hline & $15-29$ & $30-44$ & + de 45 & $15-29$ & $30-44$ & + de 45 & \\
\hline Prensa & $11 \%$ & $10 \%$ & $13 \%$ & $16 \%$ & $10 \%$ & $8 \%$ & $12 \%$ \\
\hline Not. TV & $36 \%$ & $33 \%$ & $41 \%$ & $45 \%$ & $31 \%$ & $47 \%$ & $40 \%$ \\
\hline Not. radio & $4 \%$ & $2 \%$ & $6 \%$ & $2 \%$ & $6 \%$ & $6 \%$ & $4 \%$ \\
\hline Prensa digital & $14 \%$ & $14 \%$ & $24 \%$ & $13 \%$ & $20 \%$ & $9 \%$ & $15 \%$ \\
\hline Internet & $25 \%$ & $33 \%$ & $9 \%$ & $16 \%$ & $23 \%$ & $19 \%$ & $20 \%$ \\
\hline Otro & $10 \%$ & $8 \%$ & $7 \%$ & $8 \%$ & $10 \%$ & $11 \%$ & $9 \%$ \\
\hline Total & $\begin{array}{l}100 \% \\
(n=98)\end{array}$ & $\begin{array}{l}100 \% \\
(n=49)\end{array}$ & $\begin{array}{l}100 \% \\
(n=54)\end{array}$ & $\begin{array}{c}100 \% \\
(n=255)\end{array}$ & $\begin{array}{l}100 \% \\
(n=145)\end{array}$ & $\begin{array}{l}100 \% \\
(n=118)\end{array}$ & $\begin{array}{l}100 \% \\
(n=719)\end{array}$ \\
\hline
\end{tabular}


La mayoría de quienes participaron del estudio señaló haber confiado más en la información que le proporcionaron los noticieros de televisión que en aquella que recibieron por cualquier otro medio o sistema de comunicación. La diferencia entre este recurso y el segundo mejor evaluado, en este caso internet, supera los 20 puntos porcentuales.

Los noticieros de televisión fueron no solo el medio para acceder a la mejor información, sino también en el cual tuvieron más confianza. Internet, el medio al cual recurrieron con mayor frecuencia los encuestados, pasa a un segundo sitio cuando estos le evalúan la calidad de su información y la confianza que depositan en su contenido. La mitad desconfía de los mensajes que se presentan en los medios sociales (54\%), sobre todo los hombres, quienes presentan mayores índices de desconfianza en comparación con las mujeres. Aun así, no existe ninguna diferencia estadísticamente significativa que avale este último aspecto.

Aun cuando las personas recurren muy frecuentemente a internet (de hecho, lo hacen más que con cualquier otro medio), no existe una verdadera confianza en sus contenidos. La encuesta pone de manifiesto que la confianza que existe frente a los medios sociales ligados a internet decrece sustancialmente. Con base en el estudio, se sabe que poco más de la mitad de los usuarios desconfían de toda la información que reciben de aquellos y casi cuatro de cada cinco personas incluidas en el estudio dijeron verificar la información que reciben a través de dichos medios. La desconfianza frente al contenido proveniente de las fuentes de internet ocurre independientemente de la edad o del género de los entrevistados y las entrevistadas.

\section{Conclusiones}

El estudio muestra aspectos que aluden al uso que las personas hacen de los medios de comunicación tradicionales y los medios sociales en situaciones de extrema adversidad, como la pandemia de COVID-19 en México. Se planteó como objetivo particular identificar la relación que establecieron con los medios de comunicación y con los medios sociales los ciudadanos de Monterrey y su área metropolitana durante el período de cuarentena decretado por el Estado mexicano en marzo de 2020.

Para responder al objetivo central se recurrió a la técnica de la encuesta, instrumento que permitió, en primer lugar, identificar el uso que les dieron los ciudadanos a ambos tipos de medios durante dicho período. La encuesta permitió también, en segunda instancia, conocer el medio que les proporcionó la información de mayor calidad sobre la situación que vivía la 
ciudad. Finalmente, el mismo instrumento sirvió para averiguar acerca del medio que les ofreció los contenidos más confiables sobre la pandemia.

Las evidencias halladas, finalmente, refuerzan el presupuesto que previamente había sido detectado: las personas, al identificar una condición de alto riesgo, optan por buscar información en los medios de comunicación tradicionales (sobre todo recurren a los informativos de televisión). No se trata en este caso del medio más utilizado por las personas (lo fueron los medios sociales), sino de señalar que la televisión fue el que les ofreció la información más confiable.

Como sucedió en otros sitios del mundo, también en Monterrey y su área metropolitana el uso de los medios tradicionales y de los medios sociales creció considerablemente durante el período de la cuarentena, y en condiciones además similares a aquellos (González, 2020; Vázquez, 2020; McCroclin, 2020; Elliot, 2020). El estudio indica que la mayor permanencia en el hogar permitió que los ciudadanos y las ciudadanas dedicaran más tiempo a todo tipo de medios, tanto para mantenerse informados sobre los pormenores relacionados con el tema como asimismo para entretenerse y estar en contacto con la familia, los amigos y otros grupos de la sociedad.

Internet fue el recurso de información más utilizado en la cuarentena. Este resultado coincide con las evidencias recopiladas en otros rumbos del planeta (Muno, 2020). No obstante, en condiciones de alto riesgo (como esta pandemia), los medios sociales pasan a un segundo nivel, ya que a juicio de los usuarios estos no les brindan la misma confianza que los medios de comunicación tradicionales. Así las cosas, la mayoría de los entrevistados recurrieron a los informativos de televisión, hecho coherente con los resultados hallados por académicos en diferentes eventos, que en el fondo tienen las mismas características de crisis social (Pulido et al. 2020; Norris, 2015).

Una de las explicaciones de este comportamiento (recurrir a los medios de comunicación por encima de los medios sociales en tiempos de crisis) está en la vulnerabilidad que los usuarios ven en los segundos. Los resultados exponen que, a pesar de gozar de los más altos índices de consumo digital en México, los habitantes de esta zona del país no confían del todo en los contenidos que ofrece este tipo de recursos: la mitad de ellos desconfía de sus contenidos y poco más de la mitad suele verificar la información que encuentra en aquellos. Por lo tanto, parecería ser que es la desconfianza frente a sus contenidos lo que hace que los usuarios tengan este comportamiento.

El estudio realizado por Norris (2015) ratifica que aun cuando existe una amplia participación de los medios sociales, en condiciones de alto riesgo las personas suelen preferir los informativos de televisión antes que cualquier otro recurso. El trabajo de Norris, enfocado en el comportamiento 
informativo que mostraron los ciudadanos y las ciudadanas durante los conflictos vinculados con la Primavera Árabe, destaca asimismo que los medios sociales fueron muy utilizados allí, sobre todo para establecer acuerdos y agendas entre las personas. Esta situación es verificada con los resultados del presente trabajo: en las señaladas condiciones impuestas por la pandemia, la gente usó en mayor medida este tipo de recursos con la finalidad de mantenerse en contacto con otras personas.

Si se toman en consideración los altos niveles de contagio y el rápido avance del virus en la población mexicana, es posible sostener sin duda alguna que se trató de una circunstancia de alto riesgo; no extraña, entonces, que las personas encuestadas hayan elegido los noticieros de televisión para consumir mejor información y acceder a contenidos más confiables para ellas. A la vez, que utilizaran los medios sociales para mantenerse en contacto con sus allegados preferentemente.

Finalmente, el trabajo permitió conocer que aunque los medios tradicionales no fueron el recurso más usado en Monterrey y su área metropolitana durante la cuarentena, con sus contenidos fueron los que brindaron la mayor confianza al público. La televisión, sobre todo los noticieros, surgieron de nuevo al destacarse como el recurso informativo más importante. La manera como se conduce el público para elegir el medio que a su parecer ofrece la mejor calidad y confianza informativa confirma una vez más los presupuestos que aluden al carácter activo de las audiencias, atribuido a estas desde los estudios culturales (Fuenzalida, 1989; Morley, 1993) y desde usos y gratificaciones (Katz et al., 1986). En suma, la aparición del COVID-19 y el riesgo para las personas y sus seres queridos las llevó a elegir el medio que mejor podría satisfacer sus necesidades de información y entretenimiento.

\section{Referencias}

Arévalo Avecillas, D. X. y Padilla Lozano, C. P. (2016). Medición de la confiabilidad del aprendizaje del Programa RStudio mediante alfa de Cronbach. Revista Politécnica, 37(1), 68. https:/ / revistapolitecnica.epn.edu.ec/ojs2/index.php/revista_politecnica2/article/ view/469

Elliot, R. (2020). Coronavirus in Sub-Saharan Africa: data shows changing food habits, increased testing. GeoPoll. https://www.geopoll.com/blog/2020/05/

Fuenzalida, V. (1989). Visiones y ambiciones del televidente: estudios de recepción televisiva. Ceneca.

García, D. (2019, mayo 15). NL, tercer lugar con usuarios de internet en México. Diario Milenio. https://www.milenio.com/negocios/nl-tercer-lugar-con-usuarios-deinternet\#: :text=Particularmente\%2C\%20en\%20el\%20caso\%20de,por\%20ciento\%20 de\%20la\%20poblaci\%C3\%B3n 
González, X. (2020, abril 9). Así ha cambiado el consumo de los medios a causa de la pandemia. La República. https://www.larepublica.co/globoeconomia/asi-ha-cambiadoel-consumo-de-los-medios-a-causa-de-la-pandemia-2990412 chica 9/04/2020

Greenberg, B. S. (1974). Gratifications of television viewing and their correlates for British children. En J. G. Blumler y E. Katz (Eds.), The uses of mass communications: current perspectives on gratifications research (pp. 71-92). Sage.

IAB México. (2020). Estudio de consumo de medios y dispositivos entre internautas mexicanos. El internauta frente al COVID-19. IAB México. https://www.iabmexico. com/estudios/estudio-de-consumo-de-medios-y-dispositivos-entre-internautasmexicanos-2019/

Instituto Nacional de Estadística y Geografía [INEGI]. (2021). México en cifras. Instituto Nacional de Estadística y Geografía. 2020. Censo de Población y Vivienda. https: / / censo2020.mx/

Ireton, C. y Posetti, J. (2018). Journalism, 'fake news' and disinformation: a handbook for journalism education and training. Unesco.

Katz, E., Gurevitch, M. y Hass, J. B. (1986). Usos y gratificaciones de la comunicación de masas. En M. de Moragas Spá. (Coord.), Sociología de la comunicación de masas (pp. 127-171). Gustavo Gili.

Lampos, V., Majumder, M. S., Yom-Tov, E., Edelstein, M., Moura, S., Hamada, Y., Rangaka, M. X., McKendry, R. A. y Cox, I. J. (2021). Tracking COVID-19 using online search. Nature Digital Medicine, 4(17). https://doi.org/10.1038/s41746-021-00384-W

Lazer, D. M. J., Baum, M. A., Benkler, Y., Berinsky, A. J., Greenhill, K. M., Menczer, F., Metzger, M. J., Nyhan, B., Pennycook, G., Rothschild, D., Schudson, M., Sloman, S. A., Sunstein, C. R., Thorson, E. A., Watts, D. J. y Zittrain J. L. (2018). The science of fake news. Science, 359(6380), 1094-1096. 10.1126/science.aao2998. https:/ / science.sciencemag.org/ content/359/6380/1094

Lozano, J. C. (2007). Teoría e investigación de la comunicación de masas. Pearson Educación.

Martínez, L. E. y Martínez Espinoza, L. (2014). Periodismo, Twitter y la audiencia activa [PDF]. VI Congreso Internacional de Ciberperiodismo y Web 2.0. "Las audiencias como garante de la calidad de la información en los cibermedios". Servicio editorial de la Universidad del País Vasco. https:/ / addi.ehu.es/bitstream/handle/10810/15610/UWLGCI0537. pdf? sequence $=1 \&$ isAllowed $=y$

McCroclin, S. (2020, mayo 27). Coronavirus in Uganda: impact on media consumption. GeoPoll. https://www.geopoll.com/blog/coronavirus-uganda-media/

Morley, D. (1993). Active audience theory: pendulums and pitfalls. Journal of communication, 43(4), 13-19.

Muno, M. (2020, abril 17). Coronavirus: los medios de comunicación y su credibilidad. DW. https: / / www.dw.com/es/coronavirus-los-medios-de-comunicación-y-sucredibilidad/a-53167054

Norris, P. (2015). Movilización política y redes sociales. El ejemplo de la Primavera Árabe [PDF]. Revista Iberoamericana de Comunicación, 9, 17-36. https: / / dialnet.unirioja.es/ servlet/articulo? codigo=5148403 
Oberiri Destiny, A. y Bahiyah, O. (2017). "Fake news": false fears or real concerns? Netherlands Quarterly of Human Rights, 35(4), 203-209. https://doi.org/10.1016/j. tele.2020.101475

Organización Mundial de la Salud [OMS]. (2020). Nuevo coronavirus - China. https://www. who.int/csr/don/12-january-2020-novel-coronavirus-china/es/

Park, H. y Blenkinsopp, J. (2009). Whistleblowing as planned behavior - A survey of south korean police officers. Journal of Business Ethics, 85(4), 545-556. https://doi.org/10.1007/ s10551-008-9788-y

Pennycook, G., McPhetres, J., Zhang, Y., Lu, J. G. y Rand, D. G. (2020). Fighting COVID-19 misinformation on social media: experimental evidence for a scalable accuracy-nudge intervention. Psychological Science, 31(7), 770-780.

Pulido, C. M., Villarejo Carballido, B., Redondo Sama, G. y Gómez, A. (2020). COVID-19 infodemic: more retweets for science-based information on coronavirus than for false information. International Sociology, 1-16. http:/ / dx.doi.org/10.1177/0268580920914755

Stoychev, K. (2020, junio 30). Gallup: el miedo al coronavirus crece en todo el mundo. DW. https://www.dw.com/es/gallup-el-miedo-al-coronavirus-crece-en-todo-elmundo/a-53190509

Thompson, N., Wang, X. y Daya, P. (2019). Determinants of news sharing behavior on social media. Journal of Computer Information Systems, 60(6), 593-601. https:// doi.org/10.108 0/08874417.2019.1566803

Vázquez, R. (2020, marzo 26). Durante la crisis del COVID-19 los medios tradicionales ganan credibilidad. Forbes. https://www.forbes.com.mx/durante-la-crisis-del-COVID-19-losmedios-tradicionales-ganan-credibilidad/

Zhou, X. y Zafarani, R. (2020). Fake news: a survey of research, detection methods, and opportunities. ACM Computing Surveys, 53(5). https:// doi.org/10.1145/3395046 